\title{
Requirement for two copies of RNA polymerase $\alpha$ subunit C-terminal domain for synergistic transcription activation at complex bacterial promoters
}

\author{
Georgina S. Lloyd, ${ }^{1}$ Wei Niu, ${ }^{2,3}$ John Tebbutt, ${ }^{1}$ Richard H. Ebright, ${ }^{2}$ and Stephen J.W. Busby ${ }^{1,4}$ \\ ${ }^{1}$ School of Biosciences, The University of Birmingham, Edgbaston, Birmingham B15 2TT, United Kingdom; ${ }^{2}$ Howard Hughes \\ Medical Institute, Waksman Institute, and Department of Chemistry, Rutgers University, \\ Piscataway, New Jersey 08854, USA
}

\begin{abstract}
Transcription activation by the Escherichia coli cyclic AMP receptor protein (CRP) at different promoters has been studied using RNA polymerase holoenzyme derivatives containing two full-length $\alpha$ subunits, or containing one full-length $\alpha$ subunit and one truncated $\alpha$ subunit lacking the $\alpha$ C-terminal domain ( $\alpha$ CTD). At a promoter having a single DNA site for CRP, activation requires only one full-length $\alpha$ subunit. Likewise, at a promoter having a single DNA site for CRP and one adjacent UP-element subsite (high-affinity DNA site for $\alpha$ CTD), activation requires only one full-length $\alpha$ subunit. In contrast, at promoters having two DNA sites for CRP, or one DNA site for CRP and two UP-element subsites, activation requires two full-length $\alpha$ subunits. We conclude that a single copy of $\alpha$ CTD is sufficient to interact with one CRP molecule and one adjacent UP-element subsite, but two copies of $\alpha$ CTD are required to interact with two CRP molecules or with one CRP molecule and two UP-element subsites.
\end{abstract}

[Keywords: Transcription activation; cAMP receptor protein; RNA polymerase $\alpha$ subunit; CRP-dependent promoters]

Received June 3, 2002; revised version accepted July 29, 2002.

Escherichia coli RNA polymerase holoenzyme (RNAP) has subunit composition $\alpha_{2} \beta \beta^{\prime} \omega \sigma$ (Ebright 2000). The major determinants of RNAP for promoter recognition reside in the $\sigma$ subunit, which makes direct sequencespecific contacts with promoter -10 and -35 elements (for review, see Busby and Ebright 1994; Gross et al. 1998). However, at many promoters, the RNAP $\alpha$ subunit also plays an important role in promoter recognition (for review, see Busby and Ebright 1994; Gourse et al. 2000). The RNAP $\alpha$ subunit consists of two separate domains connected by a flexible linker (Blatter et al. 1994; Jeon et al. 1995). The main function of the RNAP $\alpha$ subunit $\mathrm{N}$-terminal domain $(\alpha \mathrm{NTD}$; residues $8-235)$ is to provide a scaffold for the assembly of RNAP, whereas the main function of the RNAP $\alpha$ subunit C-terminal domain ( $\alpha$ CTD; residues 249-329) is to interact with promoter DNA to increase the initial binding of RNAP. At many promoters, $\alpha \mathrm{CTD}$ interacts with one or more $\sim 9$ bp A/T-rich DNA sequences located upstream of the -35

\footnotetext{
${ }^{3}$ Present address: Department of Molecular and Cellular Biology, Harvard University, Cambridge, Massachusetts 02138, USA.

${ }^{4}$ Corresponding author.

E-MAIL s.j.w.busby@bham.ac.uk; FAX 44-121-414-7366

Article and publication are at http://www.genesdev.org/cgi/doi/10.1101/ gad.237502.
}

element (UP-element subsites; Estrem et al. 1999; Gourse et al. 2000). Each of the two copies of $\alpha$ CTD in $\mathrm{RNAP}-\alpha \mathrm{CTD}^{\mathrm{I}}$ and $\alpha \mathrm{CTD}^{\mathrm{II}}-\mathrm{can}$ interact independently with a single UP-element subsite (Estrem et al. 1999), with residues 264-269 and 296-302 (265 determinant; Gaal et al. 1996; Murakami et al. 1996) making direct contact with the DNA minor groove (Naryshkin et al. 2000; Ross et al. 2001; Yasuno et al. 2001).

A second function of $\alpha \mathrm{CTD}$ is to serve as a target for transcriptional activators. One such transcriptional activator is the E. coli cAMP receptor protein [CRP; also referred to as catabolite activator protein (CAP)], which activates $>100$ genes in response to glucose starvation and other stresses (for review, see Kolb et al. 1993). The activity of CRP is triggered by binding of cAMP. CRP functions as a homodimer and, at target promoters, binds and sharply bends a 22-bp twofold-symmetric DNA site (Schultz et al. 1991; Parkinson et al. 1996). CRP activates transcription initiation at most target promoters by making direct protein-protein interactions with $\alpha \mathrm{CTD}$ that recruits $\alpha \mathrm{CTD}$, and hence the rest of RNAP, to promoter DNA (for review, see Busby and Ebright 1994, 1999). Mutational analysis indicates that the determinant of CRP responsible for $C R P-\alpha C T D$ interaction is an $\sim 14 \times 11 \AA$ surface located adjacent to the helix-turn- 
helix DNA-binding motif of CRP [activating region 1 (AR1); residues 156-164; Niu et al. 1994]. Single aminoacid substitutions in AR1 (e.g., TA158, HL159) interfere with CRP $-\alpha C T D$ interaction and reduce the ability of CRP to activate transcription, although they do not affect the ability of CRP to bind cAMP, to bind to DNA, or to bend DNA. Mutational analysis of $\alpha \mathrm{CTD}$ indicates that the determinant of $\alpha \mathrm{CTD}$ responsible for CRP$\alpha$ CTD interaction is an $\sim 20 \times 10 \AA$ surface located adjacent to the DNA-binding motif of $\alpha$ CTD $(287$ determinant; residues 285-290 and 315-318; Savery et al. 1998, 2002). Single amino-acid substitutions in the 287 determinant (e.g., VA287, EA288) interfere with the CRP$\alpha \mathrm{CTD}$ interaction and reduce CRP-dependent transcription, although they do not affect activator-independent transcription.

Simple CRP-dependent promoters (i.e., promoters that have only one DNA site for CRP) can be grouped into two classes based on the position of the DNA sites for CRP (Busby and Ebright 1999). At class I CRP-dependent promoters, the DNA site for CRP is located upstream of the core promoter (i.e., centered near positions $-61,-71$, -81 or -92 ), and CRP recruits $\alpha$ CTD to the DNA segment immediately downstream of the DNA site for CRP (Fig. 1A). At class II CRP-dependent promoters, the DNA site for CRP overlaps the core promoter (i.e., centered near position -41 ), and CRP recruits $\alpha$ CTD to the DNA segment immediately upstream of the DNA site for CRP (and also interacts with $\alpha$ NTD; Fig. 1B; Niu et al. 1996).
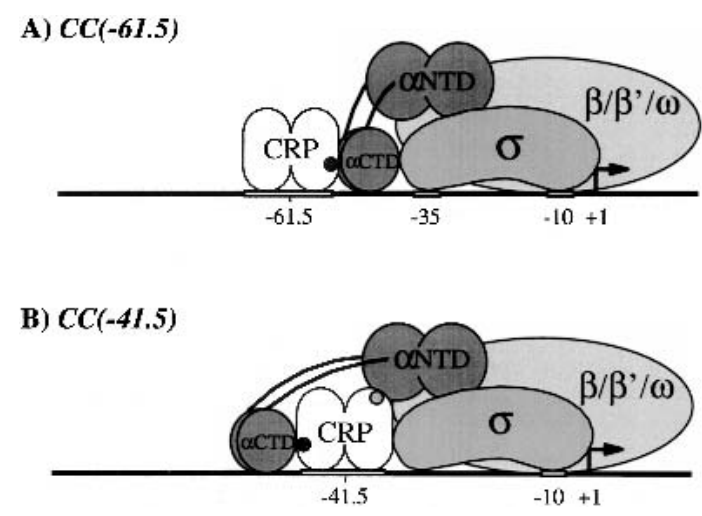

Figure 1. Transcription activation at class I and class II cyclic AMP receptor protein (CRP)-dependent promoters: published models. (A) Ternary complex of CRP, Escherichia coli RNA polymerase holoenzyme (RNAP), and a class I CRP-dependent promoter [e.g., CC(-61.5); adapted from Blatter et al. 1994; Zhou et al. 1994a,b; Busby and Ebright 1999]. Transcription activation involves direct protein-protein interaction (black filled circle) between AR1 of the downstream subunit of CRP and the 287 determinant of $\alpha$ C-terminal domain $(\alpha C T D)$. (B) Ternary complex of CRP, RNAP, and a class II CRP-dependent promoter [e.g., $C C(-41.5)$; adapted from Niu et al. 1996; Busby and Ebright 1999]. Transcription activation involves both (1) direct proteinprotein interaction (black filled circle) between AR1 of the upstream subunit of CRP and the 287 determinant of $\alpha$ CTD, and (2) direct protein-protein interaction (grey filled circle) between AR2 in the downstream subunit of CRP and $\alpha$ subunit $\mathrm{N}$-terminal domain $(\alpha \mathrm{NTD})$.
At each of these classes of CRP-dependent promoters, CRP interacts with only one of the two copies of $\alpha$ CTD in RNAP (Zou et al. 1993; Busby and Ebright 1999; Niu 1999; W. Niu and R.H. Ebright, unpubl.). Therefore, in principle, the second copy of $\alpha \mathrm{CTD}$ is available for potential interactions with a second molecule of CRP, or a molecule of another activator that functions by interacting with $\alpha$ CTD (Belyaeva et al. 1998; Busby and Ebright 1999; Langdon and Hochschild 1999).

The major aim of the work presented here has been to obtain direct evidence that although only one copy of $\alpha \mathrm{CTD}$ is required for CRP-dependent transcription at promoters having one DNA site for CRP, two copies of $\alpha \mathrm{CTD}$ are required for CRP-dependent transcription at promoters having two DNA sites for CRP. To achieve this aim, we analyzed CRP-dependent transcription at a class I CRP-dependent promoter [CC(-61.5)], at a class II CRP-dependent promoter [CC(-41.5)], and at derivatives thereof having a second DNA site for CRP, using RNAP containing two full-length $\alpha$ subunits or containing one full-length $\alpha$ subunit and one truncated $\alpha$ subunit lacking $\alpha$ CTD.

A second aim of this work has been to address a longstanding point of contention, namely, whether a single copy of $\alpha$ CTD is able to interact productively with both CRP and DNA. We have proposed that $\alpha$ CTD contacts CRP and DNA through distinct nonoverlapping determinants (with the 287 determinant contacting CRP, and the 265 determinant contacting DNA; Savery et al. 1998, 2002; Busby and Ebright 1999), and that $\alpha$ CTD productively contacts both CRP and DNA in CRP-dependent transcription complexes (Blatter et al. 1994; Busby and Ebright 1994, 1999; Tang et al. 1994; Zhou et al. 1994b; Belyaeva et al. 1998; Savery et al. 1998, 2002). However, Ishihama and others, following a study of substitutions in $\alpha$ CTD that reduce CRP-dependent activation of the lac promoter, proposed that $\alpha \mathrm{CTD}$ contacts CRP and DNA through a single determinant (or two extensively overlapping determinants). Thus, one copy of $\alpha$ CTD can contact CRP or DNA but cannot contact both CRP and DNA (Murakami et al. 1996; Ishihama 1997; Ozoline et al. 2000). To resolve this issue, we analyzed CRP-dependent transcription by an RNAP derivative having only one full-length $\alpha$ subunit at a class II CRP-dependent promoter with a single UP-element subsite located immediately adjacent to the DNA site for CRP.

\section{Results}

Full activation at a CRP-dependent promoter having two DNA sites for CRP requires both copies of $\alpha C T D$ : class I promoter derivative having a second DNA site for CRP

To determine the number of copies of $\alpha$ CTD required for CRP-dependent transcription at a class I promoter derivative having a second DNA site for CRP, we performed experiments with the $C C(-61.5)$ promoter, a class I CRP-dependent promoter having a consensus DNA site for CRP centered at position -61.5 (Fig. 2A, top; Gaston 
A)

$C C(-6) .5)$

$\operatorname{cC}(-93.5) \operatorname{cc}(-61.5)$

B)

$\operatorname{cc}(-41.5)$

$\operatorname{CC}(-90.5) \operatorname{CC}(-41.5)$

C)

$\alpha(-59.5) \operatorname{cc}(-41,5)$

D)

$c c(-69.5) \alpha(-51.5) \alpha(-41.5)$

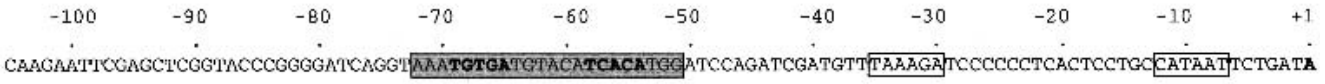

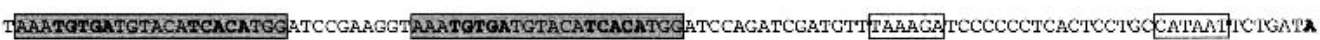

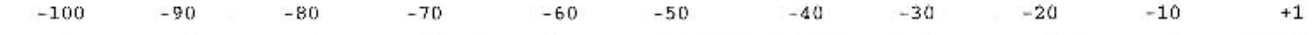

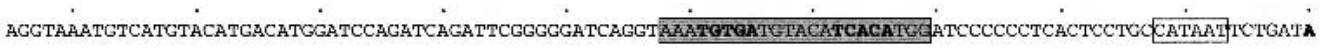

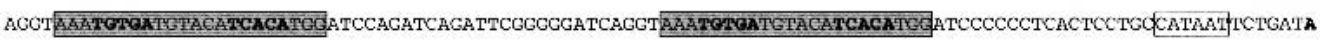

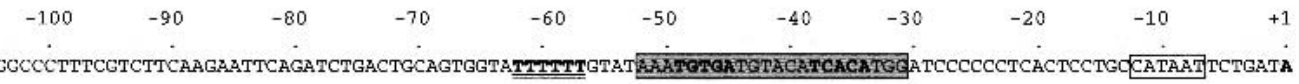

$$
-100
$$

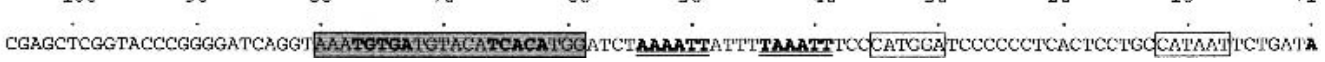

Figure 2. Promoters analyzed in this work. Promoter -10 and -35 elements are shown as open boxes; DNA sites for cyclic AMP receptor protein (CRP), as shaded boxes (with critical TGTGA/TCACA elements in boldface), and 6-bp A/T-tracts constituting UP-element subsites are doubly underlined and in boldface. (A) Class I CRP-dependent promoter and derivative with second DNA site for CRP. (B) Class II CRP-dependent promoter and derivative with second DNA site for CRP. (C) CRP-dependent promoter derivative with one UP-element subsite adjacent to DNA site for CRP. (D) CRP-dependent promoter derivative with two UP-element subsitesone adjacent to DNA site for CRP, and one not adjacent to DNA site for CRP.

et al. 1990), and with the $C C(-93.5) C C(-61.5)$ promoter, a derivative of $C C(-61.5)$ having an additional consensus DNA site for CRP centered at position -93.5 (Fig. 2A, bottom; Tebbutt et al. 2002). The presence of the additional DNA site for CRP in $C C(-93.5) C C(-61.5)$ results in a higher level of CRP-dependent transcription in vitro (Fig. 3, lanes 2,8) and in vivo (three- to fourfold synergistic effect; Table 1; Joung et al. 1993; Langdon and Hochschild 1999; Tebbutt et al. 2002).

We performed experiments using RNAP derivatives having two full-length $\alpha$ subunits, or one full-length $\alpha$ subunit and one truncated $\alpha$ subunit lacking $\alpha$ CTD. We prepared RNAP derivatives by co-expressing, respectively, genes encoding $\alpha, \beta, \beta^{\prime}, \omega, \sigma^{70}$, and hexahistidinetagged $\alpha$, or genes encoding $\alpha, \beta, \beta^{\prime}, \omega, \sigma^{70}$, and hexahistidine-tagged [RA45] $\alpha(1-235)$ (wherein the RA45 substitution prevents an $\alpha$ derivative from occupying the $\beta$-associated $\alpha^{\mathrm{I}}$ site within RNAP, and thereby restricts an $\alpha$ derivative to the $\beta^{\prime}$-associated $\alpha^{\mathrm{II}}$ site within RNAP; Murakami et al. 1997; Estrem et al. 1999; Niu 1999), lysing cells, and performing metal ion-affinity chromatography (Niu et al. 1996; Estrem et al. 1999; Niu 1999).

Figure 3, lanes 1-6, present results of transcription experiments with $C C(-61.5)$ and RNAP derivatives having two full-length $\alpha$ subunits, or one full-length $\alpha$ subunit and one truncated $\alpha$ subunit lacking $\alpha$ CTD. The results verify that transcription at $C C(-61.5)$ is CRP-dependent and AR1-dependent (Fig. 3, lanes 1-3). In addition, the results show that transcription at $C C(-61.5)$ is unaffected by truncation of one $\alpha$ subunit (Fig. 3, lanes 2,5), indicating that only one copy of $\alpha \mathrm{CTD}$ is required at $C C(-61.5)$.

Figure 3, lanes 7-12, presents results of parallel transcription experiments with $C C(-93.5) C C(-61.5)$. At
$C C(-93.5) C C(-61.5)$, as at $C C(-61.5)$, transcription is CRP-dependent and AR1-dependent (Fig. 3, lanes 7-9). However, in contrast to the situation at $C C(-61.5)$, tran-

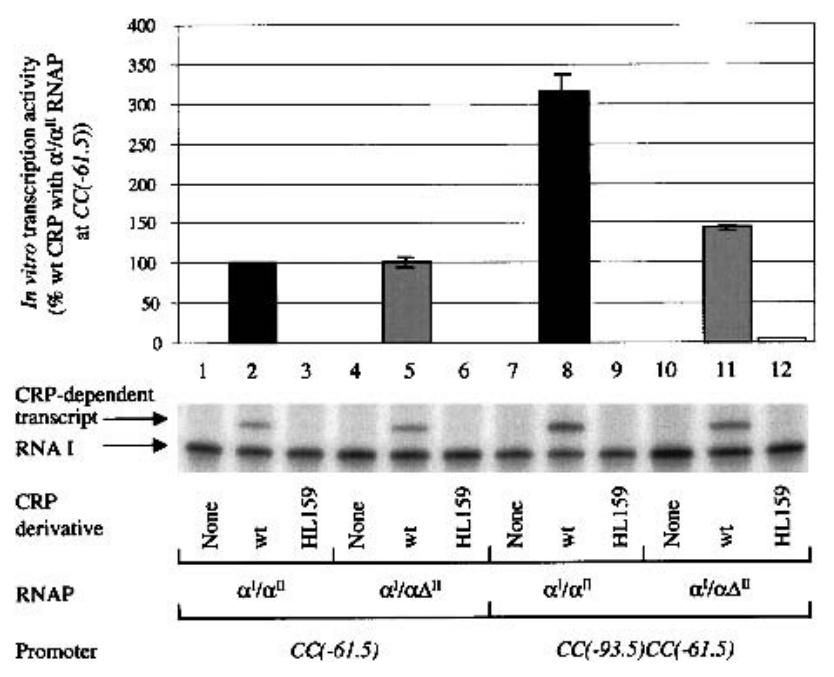

Figure 3. Full activation at a cyclic AMP receptor protein (CRP)-dependent promoter having two DNA sites for CRP requires both copies of $\alpha$ C-terminal domain $(\alpha \mathrm{CTD})$ : Class I promoter derivative having a second DNA site for CRP. The figure shows results of transcription experiments at CC(-61.5) (lanes 1-6; sequence in Fig. 2A, top) and CC(-93.5)CC(-61.5) (lanes 7-12; sequence in Fig. 2A, bottom), using Escherichia coli RNA polymerase holoenzyme (RNAP) derivatives with two fulllength $\alpha$ subunits $\left(\alpha^{\mathrm{I}} / \alpha^{\mathrm{II}}\right)$ and with one full-length and one truncated $\alpha$ subunit $\left(\alpha^{\mathrm{I}} / \alpha \Delta^{\mathrm{II}}\right)$. Yields of transcripts from $C C(-61.5)$ and $C C(-93.5) C C(-41.5)$ are normalized with reference to the control RNA I transcript. 
Lloyd et al.

Table 1. Activity of different promoters

\begin{tabular}{lc}
\hline Promoter & $\begin{array}{c}\text { Expression } \\
\text { ( } \beta \text {-galactosidase units) }\end{array}$ \\
\hline$C C(-61.5)$ & 390 \\
$C C(-93.5) C C(-61.5)$ & 1510 \\
$C C(-41.5)$ & 460 \\
$C C(-90.5) C C(-41.5)$ & 1600 \\
$X(-59.5) C C(-41.5)$ & 410 \\
$\alpha(-59.5) C C(-41.5)$ & 2585 \\
$C C(-69.5) \alpha(-51.5) \alpha(-41.5)$ & 1450 \\
\hline
\end{tabular}

Table 1 shows $\beta$-galactosidase activities in DH5 $\alpha$ lac cells carrying the lac expression vector plasmid, pRW50, containing different promoters, as listed. The measured activities (listed in standard Miller units) give an estimation of in vivo cyclic AMP receptor protein $(\mathrm{CRP})$-dependent promoter activity (Lodge et al. 1992). Activities were measured in cells grown aerobically in L-broth containing $35 \mu \mathrm{g} / \mathrm{mL}$ tetracycline exactly as in our previous studies (Law et al. 1999; Tebbutt et al. 2002)

scription at $C C(-93.5) C C(-61.5)$ is reduced by truncation of one $\alpha$ subunit (Fig. 3, lanes 8,11)-with the synergistic effect of the second DNA site for CRP being, within error, lost (Fig. 3, lanes 5,11)-indicating that two copies of $\alpha \mathrm{CTD}$ are required for full, synergistic activation at $C C(-93.5) C C(-61.5)$.

Full activation at a CRP-dependent promoter having two DNA sites for CRP requires both copies of $\alpha C T D$ : class II promoter derivative having a second DNA site for CRP

To determine the number of copies of $\alpha \mathrm{CTD}$ required for CRP-dependent transcription at a class II promoter derivative having a second DNA site for CRP, we performed experiments comparing the $C C(-41.5)$ promoter, a class II CRP-dependent promoter having a consensus DNA site for CRP centered at position -41.5 (Gaston et al. 1990; Fig. 2B, top), and the $C C(-90.5) C C(-41.5)$ promoter, a derivative of $C C(-41.5)$ having an additional consensus DNA site for CRP centered at position -90.5 (Fig. 2B, bottom; Busby et al. 1994; Belyaeva et al. 1998). The presence of the additional DNA site for CRP in $C C(-90.5) C C(-41.5)$ results in a higher level of CRP-dependent transcription in vitro (Fig. 4, lanes 2,8) and in vivo (three- to fourfold synergistic effect; Table 1; Busby et al. 1994; Belyaeva et al. 1998).

Figure 4, lanes 1-6, presents results of transcription experiments with $C C(-41.5)$ and RNAP derivatives having two full-length $\alpha$ subunits, or one full-length $\alpha$-subunit and one truncated $\alpha$-subunit lacking $\alpha$ CTD. The results verify that transcription at $C C(-41.5)$ is CRP-dependent and AR1-dependent (Fig. 4, lanes 1-3). In addition, the results show that transcription at $C C(-41.5)$ is unaffected by truncation of one $\alpha$ subunit (Fig. 4, lanes $2,5)$, indicating that only one copy of $\alpha \mathrm{CTD}$ is required at CC(-41.5).

Figure 4, lanes 7-12, present results of parallel transcription experiments with $C C(-90.5) C C(-41.5)$. At
$C C(-90.5) C C(-41.5)$, transcription is CRP-dependent and AR1-dependent (Fig. 4, lanes 7-9), as at CC(-41.5). However, in contrast to the situation at $C C(-41.5)$, transcription at $C C(-90.5) C C(-41.5)$ is reduced by truncation of one $\alpha$ subunit (Fig. 4, lanes 8,11)-with the synergistic effect of the second DNA site for CRP being, within error, fully lost (Fig. 4, lanes 5,11)-indicating that two copies of $\alpha \mathrm{CTD}$ are required for full synergistic activation at $C C(-90.5) C C(-41.5)$.

Full activation at a CRP-dependent promoter having a DNA site for CRP and one adjacent UP-element subsite requires only one copy of $\alpha C T D$

To determine the number of copies of $\alpha \mathrm{CTD}$ required for CRP-dependent transcription at a promoter having a single DNA site for CRP and one adjacent UP-element subsite, we performed experiments with the $\alpha(-59.5) C C(-41.5)$ promoter (Fig. 2C), a derivative of $C C(-41.5)$ having a consensus UP-element subsite (Estrem et al. 1999/ positioned adjacent to the DNA site for CRP and phased optimally relative to the DNA site for CRP $\left(\mathrm{T}_{6}: \mathrm{A}_{6}\right.$ tract centered $18 \mathrm{bp}$ from the centre of the DNA site for CRP; see Lloyd et al. 1998). The presence of the consensus UP-element subsite in $\alpha(-59.5) C C(-41.5)$ results in a greater than fivefold higher level of CRPdependent transcription relative to $X(-59.5) C C(-41.5)$, a derivative of $C C(-41.5)$ having a DNA sequence with no specific determinants for interaction with $\alpha$ CTD positioned adjacent to the DNA site for CRP ["No-UP" se-
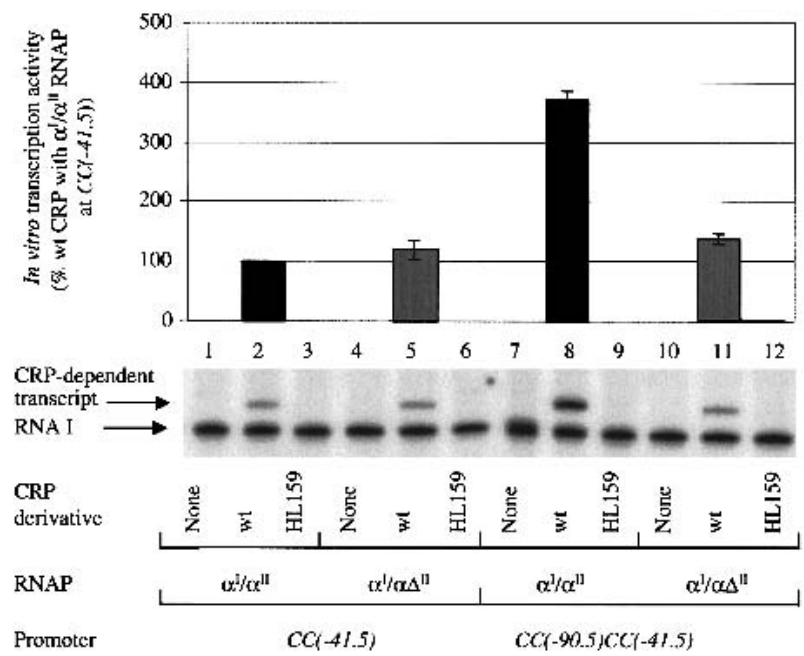

Figure 4. Full activation at a cyclic AMP receptor protein (CRP)-dependent promoter having two DNA sites for CRP requires both copies of $\alpha$ C-terminal domain $(\alpha \mathrm{CTD})$ : Class II promoter derivative having a second DNA site for CRP. Results of transcription experiments at $C C(-41.5)$ (lanes 1-6; sequence in Fig. 2B, top) and $C C(-90.5) C C(-41.5)$ (lanes 7-12; sequence in Fig. 2B, bottom), using Escherichia coli RNA polymerase holoenzyme (RNAP) derivatives with two full-length $\alpha$ subunits $\left(\alpha^{\mathrm{I}} / \alpha^{\mathrm{II}}\right)$ and with one full-length and one truncated $\alpha$ subunit $\left(\alpha^{\mathrm{I}} / \alpha \Delta^{\mathrm{II}}\right)$. Yields of transcripts from $C C(-41.5)$ and $C C(-90.5)$ $C C(-41.5)$ are normalized with reference to the control RNA I transcript. 
quence of Estrem et al. (1999); greater than fivefold "synergistic effect"; Table 1; Lloyd et al. 1998].

Figure 5 presents results of transcription experiments with $\alpha(-59.5) C C(-41.5)$ and RNAP derivatives having two full-length $\alpha$ subunits, or one full-length $\alpha$ subunit and one truncated $\alpha$ subunit lacking $\alpha \mathrm{CTD}$. The results verify that transcription at $\alpha(-59.5) C C(-41.5)$ is CRPdependent and AR1-dependent (Fig. 5, lanes 1-3). In addition, the results show that transcription at $\alpha(-59.5) C C(-41.5)$ is unaffected by truncation of one $\alpha$ subunit (Fig. 5, lanes 2,5), indicating that only one copy of $\alpha$ CTD is required for full synergistic activation at $\alpha(-59.5) C C(-41.5)$. We conclude that a single copy of $\alpha \mathrm{CTD}$ is sufficient for functional interaction with both CRP and an adjacent UP-element subsite.

\section{Full activation at a CRP-dependent promoter having a DNA site for CRP and two UP-element subsites requires two copies of $\alpha C T D$}

To determine the number of copies of $\alpha \mathrm{CTD}$ required for CRP-dependent transcription at a promoter having a single DNA site for CRP and two UP-element subsites, we performed experiments with the $C C(-69.5) \alpha(-51.5) \alpha(-41.5)$ promoter (Fig. 2D), a promoter having a DNA site for CRP centered at position -69.5 and the $\operatorname{rrn} B$ P1 UP-element, which contains two UP-element subsites (Estrem et al. 1999), positioned immediately downstream of the DNA site for CRP and phased optimally relative to the DNA site for CRP (UP-element subsites centered 18 and 28 bp from the center of the DNA site for CRP; Lloyd et
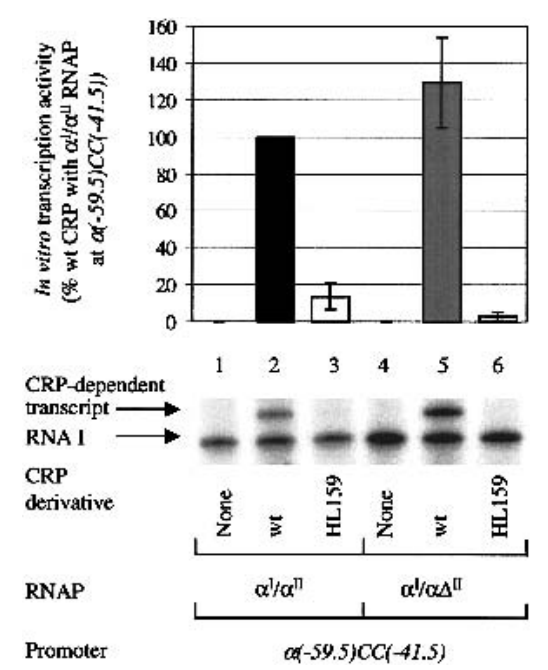

Figure 5. Full activation at a cyclic AMP receptor protein (CRP)-dependent promoter having a DNA site for CRP and one adjacent UP-element subsite requires only one copy of $\alpha \mathrm{C}$ terminal domain $(\alpha \mathrm{CTD})$. Results of transcription experiments at $\alpha(-59.5) C C(-41.5)$ (sequence in Fig. 2C) using Escherichia coli RNA polymerase holoenzyme (RNAP) derivatives with two full-length $\alpha$ subunits $\left(\alpha^{\mathrm{I}} / \alpha^{\mathrm{II}}\right)$ and with one full-length and one truncated $\alpha$ subunit $\left(\alpha^{\mathrm{I}} / \alpha \Delta^{\mathrm{II}}\right)$. Yields of transcripts from $\alpha(-59.5) C C(-41.5)$ are normalized with reference to the control RNA I transcript.

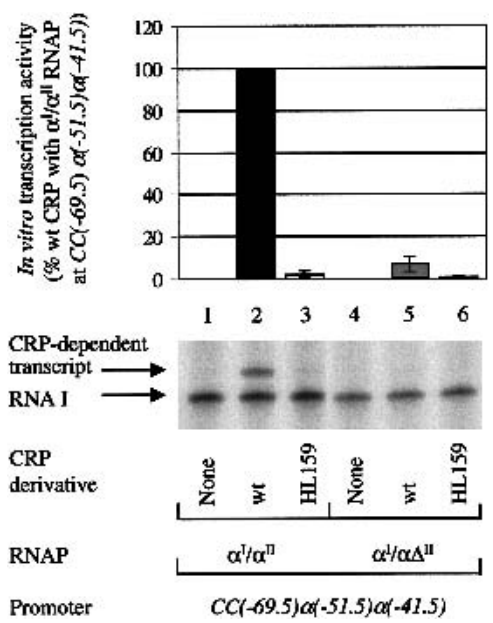

Figure 6. Full activation at a cyclic AMP receptor protein (CRP)-dependent promoter having a DNA site for CRP and two UP-element subsites requires two copies of $\alpha \mathrm{C}$-terminal domain $(\alpha \mathrm{CTD})$. Results of transcription experiments at $C C(-69.5) \alpha(-51.5) \alpha(-41.5)$ (sequence in Fig. 2D) using Escherichia coli RNA polymerase holoenzyme (RNAP) derivatives with two full-length $\alpha$ subunits $\left(\alpha^{\mathrm{I}} / \alpha^{\mathrm{II}}\right)$ and with one full-length and one truncated $\alpha$ subunit $\left(\alpha^{\mathrm{I}} / \alpha \Delta^{\mathrm{II}}\right)$. Yields of transcripts from $C C(-69.5) \alpha(-51.5) \alpha(-41.5)$ are normalized with reference to the control RNA I transcript.

al. 1998). The presence of the $r r n B$ P1 UP-element results in a greater than fivefold higher level of CRP-dependent transcription (Table 1; Savery et al. 1995; Law et al. 1999).

Figure 6 presents results of transcription experiments with $C C(-69.5) \alpha(-51.5) \alpha(-41.5)$ and RNAP derivatives having two full-length $\alpha$ subunits, or one full-length $\alpha$ subunit and one truncated $\alpha$ subunit lacking $\alpha$ CTD. The results verify that transcription at $C C(-69.5) \alpha(-51.5) \alpha(-41.5)$ is CRP-dependent and AR1-dependent (Fig. 6, lanes 1-3). In addition, the results show that transcription at $C C(-69.5) \alpha(-51.5) \alpha(-41.5)$ is reduced by truncation of one $\alpha$ subunit (Fig. 6, lanes 2,5), indicating that two copies of $\alpha$ CTD are required for full, synergistic activation at $C C(-69.5) \alpha(-51.5) \alpha(-41.5)$. Surprisingly, with the RNAP derivatives having just one full-length $\alpha$ subunit, levels of CRP-dependent transcription are very low. This implies that transcription activation at $C C(-69.5) \alpha(-51.5) \alpha(-41.5)$ requires the binding of $\alpha \mathrm{CTD}$ both at position -41.5 and at position -51.5 (Fig. 7D).

\section{Discussion}

Our results establish that although only one copy of $\alpha \mathrm{CTD}$ is required for full activation at a CRP-dependent promoter having only one DNA site for CRP (in accord with Zou et al. 1993; Zhou et al. 1994b; Niu 1999), two copies of $\alpha \mathrm{CTD}$ are required for full activation at a CRPdependent promoter having two DNA sites for CRP (Figs. 3, 4). Furthermore, our results establish that although only one copy of $\alpha \mathrm{CTD}$ is required for full activation at a CRP-dependent promoter with a DNA site for 
Lloyd et al.
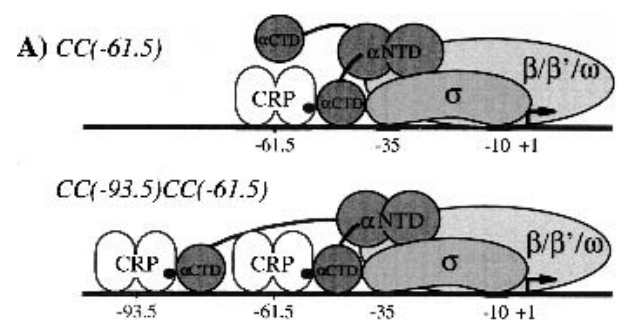

B) $C(-41.5)$

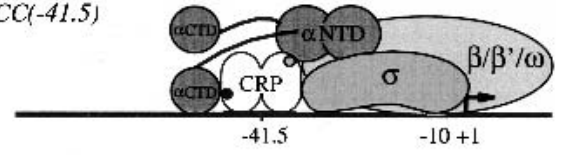

$C C(-90.5) C C(-41.5)$

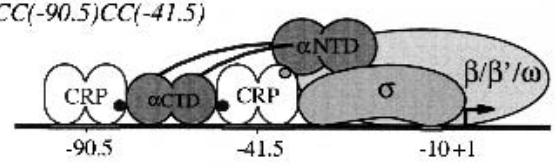

C) $0(-59.5) C C(-41.5)$

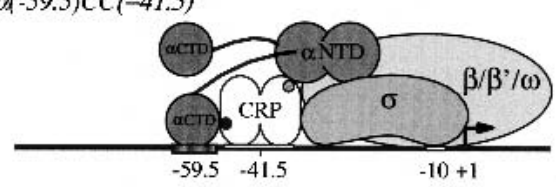

D) $(C(-69.5) \alpha(-51.5) \alpha(-41.5)$

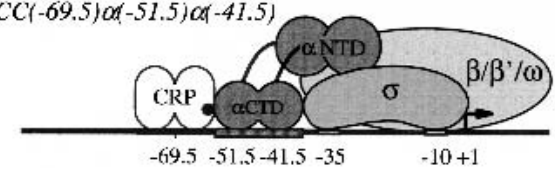

Figure 7. Models. $\alpha$ C-terminal domain $(\alpha \mathrm{CTD}), \alpha$ subunit $\mathrm{N}$ terminal domain $(\alpha \mathrm{NTD}), \beta, \beta^{\prime}$, $\omega$, and $\sigma$ denote, respectively, the Escherichia coli RNA polymerase holoenzyme (RNAP) $\alpha$ subunit $\mathrm{C}$-terminal domain, the RNAP $\alpha$ subunit $\mathrm{N}$-terminal domain, and the RNAP $\beta, \beta^{\prime}$, $\omega$, and $\sigma^{70}$ subunits. Positions of centres of DNA sites for cyclic AMP receptor protein (CRP), UP-element subsites, promoter -35 elements, promoter -10 elements, and transcription start sites are numbered. Functional AR1- $\alpha$ CTD, AR2- $\alpha$ NTD, and (UP-element subsite) $-\alpha$ CTD interactions are indicated by, respectively, black filled circles, grey filled circles, and black filled bars. For clarity, copies of $\alpha$ CTD not involved in interactions with AR1 of CRP or an UP-element subsite are drawn in a raised position, and DNA is drawn as a straight line. [In fact, copies of $\alpha$ CTD not involved in AR1- $\alpha$ CTD or (UP-element subsite)- $\alpha$ CTD interactions are likely to make nonspecific DNA- $\alpha$ CTD interactions with upstream DNA (Busby and Ebright 1999; Naryshkin et al. 2001), and both CRP and RNAP are known to bend DNA (Schultz et al. 1991; Rees et al. 1993; Parkinson et al. 1996)]. (A) Transcription activation at a class I CRP-dependent promoter (one copy of $\alpha \mathrm{CTD}$ required) and at a derivative having a second DNA site for CRP (two copies of $\alpha$ CTD required). (B) Transcription activation at a class II CRP-dependent promoter (one copy of $\alpha$ CTD required) and at a derivative having a second DNA site for CRP (two copies of $\alpha$ CTD required). (C) Transcription activation at a CRP-dependent promoter having one UP-element subsite adjacent to DNA site for CRP (one copy of $\alpha$ CTD required). (D) Transcription activation at a CRP-dependent promoter having two UP-element subsites - one adjacent to DNA site for CRP, and one not adjacent to DNA site for CRP (two copies of $\alpha$ CTD required).

CRP and an adjacent single UP-element subsite (Fig. 5), two copies of $\alpha \mathrm{CTD}$ are required for full activation at a
CRP-dependent promoter with a DNA site for CRP and two UP-element subsites (Fig. 6). Our conclusions are based on experiments with preparations of RNAP in which the $\beta$-associated $\alpha$ subunit, $\alpha^{\mathrm{I}}$, was full-length, and the $\beta^{\prime}$-associated $\alpha$ subunit, $\alpha^{\mathrm{II}}$, was truncated. Extensive data establish that $\alpha$ CTD of $\alpha^{\mathrm{I}}$ and $\alpha \mathrm{CTD}$ of $\alpha^{\mathrm{II}}$ can function interchangeably-at both class I and class II CRP-dependent promoters (Niu 1999; W. Niu and R.H. Ebright, unpubl.; cf. Estrem et al. 1999). Therefore, we are confident that identical results would have been obtained in experiments analyzing an RNAP derivative in which the $\beta$-associated $\alpha$ subunit, $\alpha^{\mathrm{I}}$, was truncated, and the $\beta^{\prime}$-associated $\alpha$ subunit, $\alpha^{\mathrm{II}}$, was full-length.

Our results document a strikingly simple mechanism for synergistic effects of two activator molecules, or of an activator molecule and a nonadjacent UP-element subsite, namely, simultaneous interactions with the two copies of $\alpha$ CTD in RNAP (Fig. 7).

Our finding that a single $\alpha \mathrm{CTD}$ suffices to manifest the full synergistic effect of CRP and an adjacent single UP-element subsite (Fig. 5, lanes 2,5) has a further implication; namely, a single $\alpha$ CTD can interact productively with both CRP and DNA. This supports the proposal that $\alpha$ CTD has distinct, nonoverlapping functional determinants for interaction with CRP and DNA, and that $\alpha$ CTD interacts simultaneously with CRP and DNA in CRP-dependent transcription complexes (Blatter et al. 1994; Busby and Ebright 1994, 1999; Tang et al. 1994; Zhou et al. 1994b; Savery et al. 1998, 2002) and is less easy to reconcile with the alternative proposal that the same surface of $\alpha$ CTD interacts with both CRP and DNA (Murakami et al. 1996; Ishihama 1997; Ozoline et al. 2000). We suggest that $\alpha$ CTD interacts simultaneously with activator and DNA in many, possibly all, activator-dependent, $\alpha$ CTD-dependent transcription complexes.

\section{Materials and methods}

\section{Strains, plasmids, and promoter derivatives}

Bacterial strains, plasmids, and promoter derivatives used in this study are listed in Table 2. EcoRI-HindIII fragments carrying promoter derivatives were cloned in vector plasmid pSR.

To measure promoter activities, the fragments were cloned into the lac expression vector, pRW50 (Lodge et al. 1992), and $\beta$-galactosidase expression in DH5 $\alpha$ cells, carrying the different plasmids, was measured exactly as in our previous studies (Law et al. 1999; Tebbutt et al. 2002).

$X(-59.5) C C(-41.5)$ was constructed by PCR, using the primer 5'-TTCAGATCTGACTGCAGTGGTACCTAGGAATTAAAT GTGATGTACATCACATGG-3' to introduce the no-UP sequence of Estrem et al. (1999) upstream of the DNA site for CRP of $C C(-41.5) . \alpha(-59.5) C C(-41.5)$ was constructed by PCR, using the primer $5^{\prime}$-TTCAGATCTGACTGCAGTGGTATTTTTTGT ATAAATGTGATGTACATCACATGG-3', to insert a consensus UP-element subsite (underlined; Estrem et al. 1999) upstream of the DNA site for CRP of $C C(-41.5)$.

\section{RNAP derivatives}

RNAP derivatives carrying two full-length $\alpha$ subunits (RNAP $\left.\alpha^{\mathrm{I}} / \alpha^{\mathrm{II}}\right)$ and carrying one full-length $\alpha$ subunit and one truncated 
Table 2. Bacterial strains, plasmids and promoter fragments

\begin{tabular}{|c|c|c|}
\hline Name & Brief description & Source/Reference \\
\hline \multicolumn{3}{|l|}{ Strains } \\
\hline DH5 $\alpha$ & E. coli $\Delta$ lac rec $A^{-}$ & Jessee 1986 \\
\hline XL1-blue & E. coli $r e c A I\left[\mathrm{~F}^{\prime} l a c 1^{q}\right]$ & Bullock et al. 1987 \\
\hline \multicolumn{3}{|l|}{ Plasmids } \\
\hline pSR & pBR322 derivative containing transcription terminator & Kolb et al. 1995 \\
\hline pREII-NH $\alpha$ & $\begin{array}{l}\text { Plasmid encoding } \mathrm{N} \text {-terminally hexahistidine-tagged } \alpha \text { under control of the } \\
\text { tandem 1ppP-lacPUV5 promoters }\end{array}$ & Niu et al. 1996 \\
\hline pREII-NH $\alpha 45 \mathrm{~A}[1-235]$ & $\begin{array}{l}\text { Plasmid encoding N-terminally hexahistidine-tagged }[\text { Ala-45] } \alpha(1-235) \text { under } \\
\text { control of the tandem lppP-lacPUV5 promoters }\end{array}$ & Niu 1999 \\
\hline pRW50 & $\begin{array}{l}\text { Low copy number, broad host range lac expression vector carrying resistance } \\
\text { to tetracycline }\end{array}$ & Lodge et al. 1992 \\
\hline \multicolumn{3}{|c|}{ 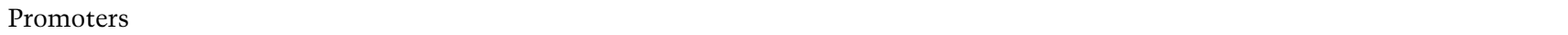 } \\
\hline$C C(-61.5)$ & $\begin{array}{l}\text { CRP-dependent promoter with consensus DNA site for CRP centred at } \\
\text { position -61.5 (Fig. 2A, top) }\end{array}$ & Gaston et al. 1990 \\
\hline$C C(-93.5) C C(-61.5)$ & $\begin{array}{l}\text { CRP-dependent promoter with consensus DNA sites for CRP centred at } \\
\text { positions }-93.5 \text { and }-61.5 \text { (Fig. } 2 \mathrm{~A} \text {, bottom) }\end{array}$ & Tebbutt et al. 2002 \\
\hline$C C(-41.5)$ & $\begin{array}{l}\text { CRP-dependent promoter with consensus DNA site for CRP centred at } \\
\text { position }-41.5 \text { (Fig. } 2 \mathrm{~B} \text {, top) }\end{array}$ & Gaston et al. 1990 \\
\hline$C C(-90.5) C C(-41.5)$ & $\begin{array}{l}\text { CRP-dependent promoter with consensus DNA sites for CRP centred at } \\
\text { positions -90.5 and }-41.5 \text { [Fig. 2B, bottom; designated MI (-90.5) in Belyaeva } \\
\text { et al. (1998)] }\end{array}$ & Belyaeva et al. 1998 \\
\hline$\alpha(-59.5) C C(-41.5)$ & $\begin{array}{l}\text { CRP-dependent promoter with consensus DNA site for CRP centred at } \\
\text { position }-41.5 \text { and consensus UP-element subsite immediately upstream of } \\
\text { the DNA site for CRP (Fig. 2C) }\end{array}$ & This work \\
\hline$X(-59.5) C C(-41.5)$ & $\begin{array}{l}\text { CRP-dependent promoter with consensus DNA site for CRP centred at } \\
\text { position }-41.5 \text { and no-UP sequence (Estrem et al. 1999) immediately } \\
\text { upstream of the DNA site for CRP }\end{array}$ & This work \\
\hline$C C(-69.5) \alpha(-51.5) \alpha(-41.5)$ & $\begin{array}{l}\text { CRP-dependent promoter with consensus DNA site for CRP centred at } \\
\text { position - } 69.5 \text { and the } r r n B \text { P1 UP-element, which contains two } \\
\text { UP-element subsites (Estrem et al. 1999), immediately downstream of the } \\
\text { DNA site for CRP [Fig. 2D; designated CC(-69.5) } \alpha(-44) \text { in Law et al.(1999)] }\end{array}$ & Law et al. 1999 \\
\hline
\end{tabular}

E. coli indicates Escherichia coli; CRP indicates cyclic AMP receptor protein.

$\alpha$ subunit lacking $\alpha \operatorname{CTD}\left(\operatorname{RNAP} \alpha^{\mathrm{I}} / \alpha \Delta^{\mathrm{II}}\right)$ were prepared from transformants of $E$. coli strain XL1-blue with, respectively, pREII-NH $\alpha$ and pREII-NH $\alpha 45 \mathrm{~A}(1-235)$, using $\mathrm{Ni}^{2+}$-NTA agarose chromatography and Mono-Q chromatography (Niu et al. 1996; Estrem et al. 1999; Niu 1999|.

\section{CRP derivatives}

Wild-type CRP and CRP HL159 were prepared as in Ghosaini et al. (1988).

\section{Transcription experiments}

To measure CRP-dependent transcription activation in vitro, DNA fragments carrying promoters were cloned upstream of the bacteriophage $\lambda$ oop terminator in vector plasmid pSR. Thus, CRP-dependent transcription initiation in vitro could be measured by the appearance of a transcript running from the cloned promoter to the oop terminator. Quantification was facilitated by the simultaneous appearance of the vector-encoded RNA I transcript, which was controlled by a factor-independent promoter unaffected by truncation of $\alpha$ CTD (Meng et al. 2000). Transcription experiments were performed in $25 \mu \mathrm{L}$ samples containing: $0.2 \mathrm{nM}$ supercoiled template DNA, $60 \mathrm{nM}$ RNAP derivative, $20 \mathrm{nM}$ CRP derivative $(40 \mathrm{nM}$ in experiments in Figs. 3, 5), $0.2 \mathrm{mM}$ cAMP, $10 \mu \mathrm{M}$ UTP, $2.5 \mu \mathrm{Ci} \alpha{ }^{-32}[\mathrm{P}]-\mathrm{UTP}$ (3000 Ci/mmole), $200 \mu \mathrm{M}$ ATP, $200 \mu \mathrm{M}$ CTP, $200 \mu \mathrm{M}$ GTP, $40 \mathrm{mM}$ Tris-acetate (pH 7.9), $200 \mathrm{mM} \mathrm{KCl} \mathrm{(100} \mathrm{mM} \mathrm{in} \mathrm{experiments} \mathrm{in}$
Fig. 3), $10 \mathrm{mM} \mathrm{MgCl}_{2}, 1 \mathrm{mM}$ dithiothreitol (DTT), and 100 $\mu \mathrm{g} / \mathrm{mL}$ bovine serum albumin. Reactions were initiated by the addition of the RNAP derivative and were terminated after 15 min at $30^{\circ} \mathrm{C}$ by the addition of $25 \mu \mathrm{L}$ stop solution $(7 \mathrm{M}$ urea, $1 \%$ SDS, $10 \mathrm{mM}$ EDTA, and $0.05 \%$ bromophenol blue, and $0.05 \%$ xylene cyanol). Products were isolated using $6 \%$ acrylamide gels containing $7 \mathrm{M}$ urea and quantified by PhophorImager analysis (Molecular Dynamics Inc.; mean \pm SD of at least three independent determinations).

\section{Acknowledgments}

This work was supported by a project grant from the United Kingdom Biotechnology and Biological Sciences Research Council to S.J.W.B., and by National Institutes of Health grant GM41376 and a Howard Hughes Medical Institute Investigatorship to R.H.E.

The publication costs of this article were defrayed in part by payment of page charges. This article must therefore be hereby marked "advertisement" in accordance with 18 USC section 1734 solely to indicate this fact.

\section{References}

Belyaeva, T.A., Rhodius, V.A., Webster, C.L., and Busby, S.J.W. 1998. Transcription activation at promoters carrying tandem 
DNA sites for the Escherichia coli cyclic AMP receptor protein: Organization of the RNA polymerase $\alpha$ subunits. $J$. Mol. Biol. 277: 789-804.

Blatter, E.E., Ross, W., Tang, H., Gourse, R.L., and Ebright, R.H. 1994. Domain organization of RNA polymerase $\alpha$ subunit: C-terminal 85 amino acids constitute a domain capable of dimerization and DNA binding. Cell 78: 889-896.

Bullock, W.O., Fernandez, J.M., and Short, J.M. 1987. XL1-blue: a high efficiency plasmid transforming recA Escherichia coli strain with $\beta$-galactosidase selection. Biotechniques 5: 376 378.

Busby, S. and Ebright, R.H. 1994. Promoter structure, promoter recognition, and transcription activation in prokaryotes. Cell 79: 743-746.

- 1999. Transcription activation by catabolite activator protein (CAP). J. Mol. Biol. 293: 199-213.

Busby, S., West, D., Lawes, M., Webster, C., Ishihama, A., and Kolb, A. 1994. Transcription activation by the Escherichia coli cyclic AMP receptor protein: receptors bound in tandem at promoters can interact synergistically. J. Mol. Biol. 241: 341-352.

Ebright, R.H. 2000. RNA polymerase: Structural similarities between bacterial RNA polymerase and eucaryotic RNA polymerase II. J. Mol. Biol. 304: 687-698.

Estrem, S.T., Ross, W., Gaal, T., Chen, Z.W., Niu, W., Ebright, R.H., and Gourse, R.L. 1999. Bacterial promoter architectures: Subsite structure of UP elements and interactions with the carboxy-terminal domain of the RNA polymerase $\alpha$ subunit. Genes \& Dev. 13: 2134-2147.

Gaal, T., Ross, W., Blatter, E.E., Tang, H., Jia, X., Krishnan, V.V., Assa-Munt, N., Ebright, R.H., and Gourse, R.L. 1996. DNAbinding determinants of the $\alpha$ subunit of RNA polymerase: Novel DNA-binding domain architecture. Genes \& Dev. 10: $16-26$.

Gaston, K., Bell, A., Kolb, A., Buc, H., and Busby, S. 1990. Stringent spacing requirements for transcription activation by CRP. Cell 62: 733-743.

Ghosaini, L.R., Brown, A.M., and Sturtevant, J.M. 1988. Scanning calorimetric study of the thermal unfolding of catabolite activator protein from Escherichia coli in the absence and presence of cyclic mononucleotides. Biochemistry 27: 5257-5261.

Gourse, R.L., Ross, W., and Gaal, T. 2000. UPs and downs in bacterial transcription initiation: Role of the $\alpha$ subunit of RNA polymerase in promoter recognition. Mol. Microbiol. 37: 687-690.

Gross, C.A., Chan, C., Dombroski, A., Gruber, T., Sharp, M., Tupy, J., and Young, B. 1998. The functional and regulatory roles of $\sigma$ factors in transcription. Cold Spring Harbor Symp. Quant. Biol. 63: 143-155.

Ishihama, A. 1997. Promoter selectivity and control of RNA polymerase. In Nucleic acids and molecular biology (eds. F. Eckstein and D. Lilley), Vol. 11. pp. 53-70. Springer, Berlin, Germany.

Jeon, Y.H., Negishui, T., Shirakawa, M., Yamazaki, T., Fujita, N., Ishihama, A., and Kyogoku, Y. 1995. Solution structure of the activator contact domain of the RNA polymerase $\alpha$ subunit. Science 270: 1495-1497.

Jessee, J. 1986. New subcloning efficiency competent cells: $>10^{6}$ transformants/ug. Focus (BRL) 8: 9-10.

Joung, J.K., Le, L.U., and Hochschild, A. 1993. Synergistic activation of transcription by Escherichia coli cyclic AMP receptor protein. Proc. Natl. Acad. Sci. 90: 3083-3087.

Kolb, A., Busby, S., Buc, H., Garges, S., and Adhya, S. 1993. Transcriptional regulation by cAMP and its receptor protein. Annu. Rev. Biochem. 62: 749-795.
Kolb, A., Kotlarz, D., Kusano, S., and Ishihama, A. 1995. Selectivity of the Escherichia coli RNA polymerase $\mathrm{E}^{38}$ for overlapping promoters and ability to support CRP activation. Nucleic Acids Res. 23: 819-826.

Langdon, R.C. and Hochschild, A. 1999. A genetic method for dissecting the mechanism of transcriptional activator synergy by identical activators. Proc. Natl. Acad. Sci. 96: 12673-12678.

Law, E.C., Savery, N.J., and Busby, S.J.W. 1999. Interactions between the Escherichia coli cAMP receptor protein and the C-terminal domain of the $\alpha$ subunit of RNA polymerase at Class I promoters. Biochem. I. 337: 415-423.

Lloyd, G.S., Busby, S.J.W., and Savery, N.S. 1998. Spacing requirements for transcription activation by an UP element at class II CRP-dependent promoters. Biochem. J. 330: 413-420.

Lodge, J., Fear, J., Busby, S., Gunasekaran, P., and Kamini, N.-R. 1992. Broad host range plasmids carrying the Escherichia coli lactose and galactose operons. FEMS Lett. 95: 271-276.

Meng, W., Savery, N.J., Busby, S.J.W., and Thomas, M.S. 2000. The Escherichia coli RNA polymerase $\alpha$ subunit linker: Length requirements for transcription activation at CRP-dependent promoters. EMBO J. 19: 1555-1566.

Murakami, K., Fujita, N., and Ishihama, A. 1996. Transcription factor recognition surface on the RNA polymerase $\alpha$ subunit is involved in contact with the DNA enhancer element. EMBO J. 15: 4358-4367.

Murakami, K., Kimura, M., Owens, J.T., Meares, C.F., and Ishihama, A. 1997. The two $\alpha$ subunits of Escherichia coli RNA polymerase are asymmetrically arranged and contact different halves of the DNA upstream element. Proc. Natl. Acad. Sci. 94: 1709-1714.

Naryshkin, N., Revyakin, A., Kim, Y., Mekler, V., and Ebright, R.H. 2000. Structural organization of the RNA polymerasepromoter open complex. Cell 101: 601-611.

Niu, W. 1999. "Identification and characterization of interactions between a transcription activator and the transcription machinery." Ph.D. dissertation. Rutgers University, New Brunswick, NJ.

Niu, W., Zhou, Y., Dong, Q., Ebright, Y.W., and Ebright, R.H. 1994. Characterization of the activating region of Escherichia coli catabolite gene activator protein (CAP) I: Saturation and alanine scanning mutagenesis. J. Mol. Biol. 243: 595602.

Niu, W., Kim, Y., Tau, G., Heyduk, T., and Ebright, R.H. 1996. Transcription activation at class II CAP-dependent promoters: Two interactions between CAP and RNA polymerase. Cell 87: 1123-1134.

Ozoline, O.N., Fujita, N., and Ishihama, A. 2000. Transcription activation mediated by the carboxyl-terminal domain of the RNA polymerase $\alpha$ subunit. J. Biol. Chem. 275: 1119-1127.

Parkinson, G., Wilson, C., Gunasekera, A., Ebright, Y.W., Ebright, R.H., and Berman, H.M. 1996. Structure of the CAPDNA complex at $2.5 \AA$ A resolution. J. Mol. Biol. 260: 395-408.

Rees, W.A., Keller, R.W., Vesenka, J.P., Yang, G., and Bustamente, C. 1993. Evidence of DNA bending in transcription complexes imaged by scanning force microscopy. Science 260: 1646-1649.

Ross, W., Ernst, A., and Gourse. R.L. 2001. Fine structure of $E$. coli RNA polymerase-promoter interactions: $\alpha$ Subunit binding to the UP element minor groove. Genes \& Dev. 15: 491-506.

Savery, N.J., Rhodius, V.A., Wing, H.J., and Busby, S.J.W. 1995. Transcription activation at Escherichia coli promoters dependent on the cyclic AMP receptor protein: Effects of binding sequences for the RNA polymerase $\alpha$-subunit. Biochem. J. 309: $77-83$. 
Savery, N.J., Lloyd, G.S, Kainz, M., Gaal, T., Ross, W., Ebright, R.H., Gourse, R.L., and Busby, S.J.W. 1998. Transcription activation at class II CRP-dependent promoters: identification of determinants in the C-terminal domain of the RNA polymerase $\alpha$ subunit. EMBO J. 17: 3439-3447.

Savery, N.J., Lloyd, G.S., Busby, S.J.W., Thomas, M.S., Ebright, R.H., and Gourse, R.L. 2002. Determinants of the C-terminal domain of the Escherichia coli RNA polymerase $\alpha$ subunit important for transcription at class I CRP-dependent promoters. J. Bacteriol. 184: 2273-2280.

Schultz, S.C., Shields, G.C., and Steitz, T.A. 1991. Crystal structure of a CAP-DNA complex: The DNA is bent by 90 degrees. Science 253: 1001-1007.

Tang, H., Severinov, K., Goldfarb, A., Fenyo, D., Chait, B., and Ebright, R.H. 1994. Location, structure and function of the target of a transcriptional activator protein. Genes \& Dev. 8: $3058-3067$.

Tebbutt, J., Rhodius, V., Webster, C., and Busby, S. 2002. Architectural requirements for optimal activation by tandem CRP molecules at a class I CRP-dependent promoter. FEMS Lett. 210: 55-60.

Yasuno, K., Yamazaki, T., Tanaka, Y., Kodama, T.S., Matsugami, A., Katahira, M., Ishihama, A., and Kyogoku, M. 2001. Interaction of the C-terminal domain of the E. coli RNA polymerase $\alpha$ subunit with the UP element: Recognizing the backbone structure in the minor groove surface. J. Mol. Biol. 306: 213-225.

Zhou, Y., Merkel, T.J., and Ebright, R.H. 1994a. Characterization of the activating region of Escherichia coli catabolite gene activator protein (CAP) II: Role at class I and class II CAP-dependent promoters. J. Mol. Biol. 243: 603-610.

Zhou, Y., Pendergrast, P.S., Bell, A., Williams, R., Busby, S., and Ebright, R.H. 1994b. The functional subunit of a dimeric transcription activator depends upon promoter architecture. EMBO I. 13: 4549-4557.

Zou, C., Fujita, N., and Ishihama, A. 1993. Assymetric arrangement of two $\alpha$ subunits within Escherichia coli RNA polymerase. Involvement of one $\alpha$ subunit in contact with cAMP receptor protein. J. Mol. Biol. 236: 1283-1288. 


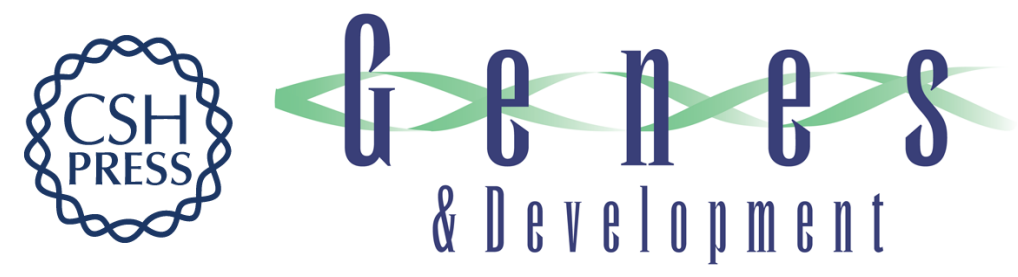

\section{Requirement for two copies of RNA polymerase $\alpha$ subunit C-terminal domain for synergistic transcription activation at complex bacterial promoters}

Georgina S. Lloyd, Wei Niu, John Tebbutt, et al.

Genes Dev. 2002, 16:

Access the most recent version at doi:10.1101/gad.237502

References This article cites 36 articles, 13 of which can be accessed free at:

http://genesdev.cshlp.org/content/16/19/2557.full.html\#ref-list-1

License

Email Alerting

Receive free email alerts when new articles cite this article - sign up in the box at the top

Service

right corner of the article or click here.

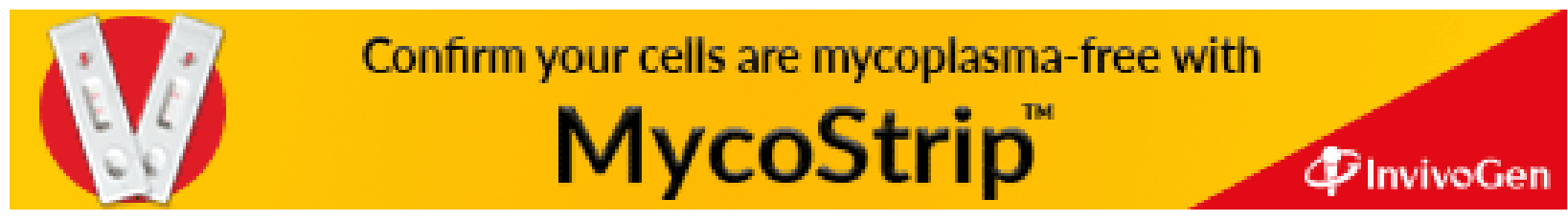

